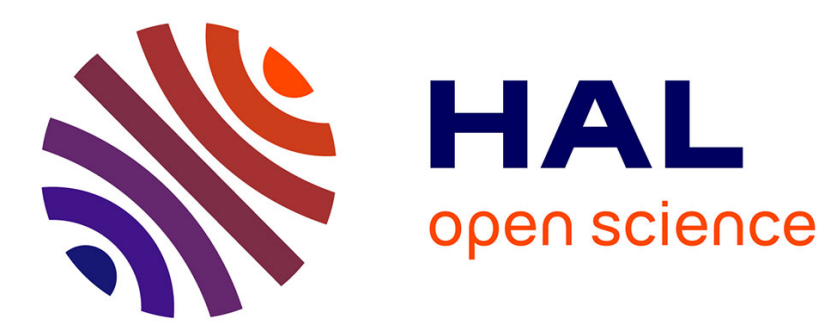

\title{
Managing coppice forests for rockfall protection: lessons from modeling
}

Anna Radtke, David Toe, Frederic Berger, Stefan Zerbe, Franck Bourrier

\section{To cite this version:}

Anna Radtke, David Toe, Frederic Berger, Stefan Zerbe, Franck Bourrier. Managing coppice forests for rockfall protection: lessons from modeling. Annals of Forest Science, 2014, 71 (4), pp.485-494. $10.1007 / \mathrm{s} 13595-013-0339-\mathrm{z}$. hal-01101752

\section{HAL Id: hal-01101752 \\ https://hal.science/hal-01101752}

Submitted on 9 Jan 2015

HAL is a multi-disciplinary open access archive for the deposit and dissemination of scientific research documents, whether they are published or not. The documents may come from teaching and research institutions in France or abroad, or from public or private research centers.
L'archive ouverte pluridisciplinaire HAL, est destinée au dépôt et à la diffusion de documents scientifiques de niveau recherche, publiés ou non, émanant des établissements d'enseignement et de recherche français ou étrangers, des laboratoires publics ou privés. 


\title{
Managing coppice forests for rockfall protection: lessons from modeling
}

\author{
Anna Radtke • David Toe • Frederic Berger • \\ Stefan Zerbe • Franck Bourrier
}

Received: 18 March 2013 / Accepted: 4 October 2013 / Published online: 30 October 2013

(C) INRA and Springer-Verlag France 2013

\begin{abstract}
- Context One eighth of Europe's forests are still managed as coppice. In some European countries, more than half of the forest exhibits coppice structures from the past or present coppice management. Many of these forests grow in the broadleaf zone of mountainous regions, often on steep slopes. Here, they play an important role in rockfall protection. However, it remains unclear how coppice forests should be structured for optimal rockfall protection or how the protection effect changes during the aging of the coppice.

- Aim A few studies have applied rock trajectory analyses, but so far, no process-based model has been used to quantify the
\end{abstract}

Handling Editor: Barry Alan Gardiner

Contributions of the co-authors Toe: running the data analysis. Bourrier: writing the paper, supervising the work, help in running the data analysis

Zerbe: coordinating the research project (named EcoRAlps) Berger: supervising the work

\footnotetext{
A. Radtke $(\bowtie) \cdot$ S. Zerbe

Faculty of Science and Technology, Free University of

Bozen-Bolzano, Piazza Università 5, 39100 Bolzano, Italy

e-mail: anna.radtke@natec.unibz.it

S. Zerbe

e-mail: stefan.zerbe@unibz.it

D. Toe $\cdot$ F. Berger $\cdot$ F. Bourrier

Irstea, UR EMGR, 2 rue de la Papeterie,

38402 Saint-Martin-d'Hères, France

D. Toe

e-mail: david.toe@irstea.fr

F. Berger

e-mail: frederic.berger@irstea.fr

F. Bourrier

e-mail: franck.bourrier@irstea.fr
}

protective effect of differently structured coppice forests. The present study compared 40 coppice patches from two chronosequences in South Tyrol, North Italy, regarding their protective effect against rocks of two sizes using the rockfall simulation model Rockyfor3D.

- Results The results indicate that coppice stands older than 30 years better protect against rockfall than medium-aged and young stands, although the old ones have lower stem densities. Surprisingly, a random stem distribution had a better protective effect than the clumped stem distribution typical for coppice stands.

- Conclusion Implications for future management are discussed in detail, including the relevance of standards in coppice forests.

Keywords Coppice forest - Protection forest - Spatial tree distribution $\cdot$ Stand structure $\cdot 3$-D rockfall simulation

\section{Introduction}

In $2000,16 \%$ of the productive forests in Europe were managed as coppice, covering a total area of 21 million ha, mainly located in Southern and Southeastern Europe. The largest areas were in France (7 million ha), Italy (3.5 million ha), Greece ( $>2$ million ha), Turkey, and Spain (Puumalainen 2001). In traditional coppice management, small areas are clear-cut every 20-30 years (Piussi 2006). After cutting, many European broadleaf species quickly sprout from the coppiced stools forming multistemmed trees (Matula et al. 2012). In many regions, some trees, called standards, are not cut for two or more rotation periods to produce seeds and ensure sexual reproduction, rather than only vegetative sprouting. In this coppice with standards (CWS) system, timber can be harvested in addition to the low-diameter firewood of the coppice shoots (Piussi 2006). 
Due to socioeconomic changes, many coppice forests are no longer used and are undergoing natural succession or are being converted into high forests (Piussi and Farrell 2000). In addition to the ecosystem services provided by coppice forests in mountainous regions, such as wood production and biodiversity conservation, this study focuses on the protection of human beings and infrastructures against natural hazards and rockfall in particular. Especially in the lower altitudes of mountainous regions, where forests mainly consist of broadleaf species, coppice management has been practiced for a long time for its recognized protection against rockfall (Autonome Provinz BozenSüdtirol 2010; Gerber and Elsener 1998). On steep, forested slopes below cliffs, which are subject to rockfall, foresters have aimed for high stem densities to create as many obstacles as possible for falling rocks. Coppice forests typically exhibit high stem densities and relatively small stem diameters, as a result of clumps formed of stems which sprout from the stools. This clustering of stems may provide an enhanced protective effect relative to equivalent but sparsely distributed stems (Jancke et al. 2009). During the aging of coppice stands, stem densities decrease, while stem diameters increase. Therefore, there is a concern that the abandonment of coppice stands leads to an increased rockfall risk. To provide a sound basis for sensible forest management plans, this study was aimed at quantifying the effect of coppice aging on their protective effect against rockfall.

An increasing number of studies show that the forest cover is an efficient and cost-effective rockfall protection structure (Wehrli et al. 2005, 2006; Dorren et al. 2007; Notaro and Paletto 2012). Optimizing forest planning to mitigate rockfall hazard, in conjunction with other ecosystems services, is of major interest. For that purpose, recent studies have focused on quantifying the protection potential of coppice forest, using empirical models based on the energy line concept (Ciabocco et al. 2009; Jancke et al. 2009). As an alternative, process-based rockfall modeling approaches allow a precise description of rockfall trajectories including impacts against trees (Dorren et al. 2006). These models have been mainly calibrated for high forest composed of large trees, focusing on singlestem impacts (Dorren and Berger 2005; Jonsson 2007; Lundstrom et al. 2009). Experimental tests with small-diameter trees and multistem impacts (Jancke 2012) have shown that the predictions from models calibrated with large-diameter trees are also relevant for coppice forests. Therefore, process-based rockfall models calibrated for high-forest stands should be suitable for studying rockfall hazard mitigation in coppice stands.

To manage coppice forests for rockfall protection, it is necessary to understand the specific characteristics of these forests which promote rockfall protection. Therefore, this paper had the aim of defining indicators for the protective function of coppice forests against rockfall propagation. These indicators are then used to test the following hypotheses:

a. The coppice-specific spatial stem distribution in clumps has the same protective effect as a random stem distribution that is usually found in high-forests.

b. The age of the coppice stand (time since the last cutting) has no effect on rockfall protection.

The ongoing coppice abandonment and overaging of many coppice forest stands in Europe, especially in mountainous regions where cutting is awkward and barely profitable, make the evolution of rockfall protection during aging to be a key question for future coppice forest management.

\section{Materials and methods}

\subsection{Study site and field sampling}

To compare the protective effect among coppice forests of different ages, we carried out inventories on 40 forest patches within two coppice stands of 2.5 and 3 ha, respectively (Table 1). Both coppice stands are close to the city of Bolzano in Northern Italy, at the southern border of the Alps. Due to the sub-Mediterranean climate with a mean annual temperature around $12{ }^{\circ} \mathrm{C}$ and a mean annual precipitation around $700 \mathrm{~mm}$, the sampled forests belong to the Orno-Ostryetum forest type (Autonome Provinz Bozen-Südtirol 2010; Table 1). Both stands have been managed as coppice or coppice with standards for decades. The mean rotation length was previously around 25 years; however, in recent decades, the coppice has been cut less frequently due to low cost-

Table 1 Site characteristics of the two sampled stands

\begin{tabular}{|c|c|c|}
\hline & $\begin{array}{l}1^{\text {st }} \text { stand: Gargazzone } \\
\text { (GA) }\end{array}$ & $\begin{array}{l}2^{\text {nd }} \text { stand: Cortaccia } \\
(\mathrm{CO})\end{array}$ \\
\hline Coordinates & $\mathrm{N} 46^{\circ} 34^{\prime} 53, \mathrm{E} 11^{\circ} 12^{\prime} 41$ & $\mathrm{~N} 46^{\circ} 19^{\prime} 20, \mathrm{E} 11^{\circ} 13^{\prime} 41$ \\
\hline Elevation & $260-430 \mathrm{~m}$ a.s.1. & 430-570 m a.s.1. \\
\hline Mean aspect & WSW & $\mathrm{E}$ \\
\hline Mean slope & $32^{\circ}$ & $35^{\circ}$ \\
\hline Bedrock & Siliceous (porphyry) & Calcareous (dolomite) \\
\hline \multirow[t]{4}{*}{ Main tree species } & Ostrya carpinifolia & Ostrya carpinifolia \\
\hline & $\begin{array}{l}\text { Quercus petrea/Quercus } \\
\text { pubescens }\end{array}$ & Fraxinus ornus \\
\hline & Fraxinus ornus & $\begin{array}{l}\text { Sorbus aria/Sorbus } \\
\quad \text { torminalis }\end{array}$ \\
\hline & Robinia pseudoacacia & Tilia cordata \\
\hline No. of plots & 19 & 21 \\
\hline Tree coordinates & Not recorded & Recorded \\
\hline
\end{tabular}

a.s.l. above sea level 
effectiveness, so that some patches are 40 years and older. The number of standards varies between patches.

Both stands display a patchwork of different age classes resulting from small clear cuts $(<0.5 \mathrm{ha})$ from different years. Within this patchwork, we carried out inventories on circular $12-\mathrm{m}$ radius plots $\left(452 \mathrm{~m}^{2}\right)$. In the first stand, 19 plots were randomly chosen from a systematic $45-\mathrm{m}$ sampling grid with 113 points from an earlier study (Radtke et al. 2013), in a way that the different age classes were equally represented. In the second stand, patch age was unknown. Therefore, it was estimated visually, and sampling plots were positioned randomly along the chronosequence, again in such a way that the different age classes were equally represented.

Plot inventory comprised of the coordinates and the diameter at breast height (dbh) of each living stem with $\mathrm{dbh} \geq 3 \mathrm{~cm}$. The dbh was measured standing uphill of the tree. Furthermore, we recorded which stems belonged to the same stool and the circumferences of the stool in the direction of the slope and orthogonal to that. These values were used to calculate the ellipse in Section 2.3. Tree coordinates were measured as the distance and angle from the plot center using an ultrasound distance-measuring device (Vertex VL5, Haglöf Company Group, Sweden) and a compass on a tripod. The high stem densities of coppice stands, especially in young stands, make the recording of these measurements very timeconsuming. Thus, due to time constraints, tree coordinates could be measured in the second stand (CO) only (Table 1).

\subsection{Rockfall model}

The rockfall protection of the different coppice forests was calculated with the process-based rockfall simulation code Rockyfor3D. It simulates the propagation of rocks down a slope by successive sequences of free flights through the air, rebounds on the slope surface, and impacts against trees (Dorren 2012). Required site information is the following: topography, position of the rock departure zones, soil properties, and the position and diameters of each tree along the slope. The impact of a rock on a tree is detected when the distance between the positions of the rock and of the tree is less than half of the dbh of the tree. It results in the loss of part of the rock's kinetic energy depending on the tree diameter, on the vertical and horizontal locations of the impact point on the tree, and on the rock trajectory before impact (Dorren 2012). The influence of these parameters on rock energy loss was calibrated using real-size rockfall experiments on forested slopes (Dorren and Berger 2005).

In order to focus on the comparison between the protection capacities of the different forest covers, the same virtual topography and falling rocks properties were used for all simulations. Only the forest covering the slope was changed.

A digital terrain model (DTM) with a $2-\mathrm{m}$ resolution describing the topography of the virtual study site was generated using a regular slope of $35^{\circ}$ (Fig. 1). To ensure that the results were not severely influenced by collisions with the trees immediately in front of the rock departure area, 100 different departure zones were placed at the top of the slope. One million spherical rocks were dropped with an initial fall height of $5 \mathrm{~m}$ per simulation, i.e., 10,000 per departure cell. Two rock volumes were tested: 0.25 and $0.5 \mathrm{~m}^{3}$. As was most frequently observed in the field, the chosen soil type was a talus slope composed of rocks having a diameter greater than $10 \mathrm{~cm}$ (Rockyfor3D, soil type 4; Dorren 2012). The roughness classes required in Rockyfor3D were set to $\mathrm{rg} 70,0.05 \mathrm{~m}$; $\mathrm{rg} 20,0.2 \mathrm{~m}$; and $\operatorname{rg} 10,0.3 \mathrm{~m}$. These correspond to the obstacle height that a rock encounters during the rebound in 70,20, and $10 \%$ of the cases, respectively.

For each simulation with a different virtual forest, two indicators of the protective effect were measured at predefined "measuring lines," placed every $6 \mathrm{~m}$ for simulations with $0.25 \mathrm{~m}^{3}$ rocks and every $10 \mathrm{~m}$ for simulations with $0.5 \mathrm{~m}^{3}$ rocks. The measured indicators were the number of passing rocks and the $95 \%$ quantile of the energy $\left(E_{95}\right)$ of all rocks passing through the line (Fig. 1, Table 2). Both types of indicator have already been used in previous research works to locate and design rockfall protection structures such as embankments (Lambert et al. 2013).

\subsection{Virtual forest}

Based on the dbh distribution, stem density and spatial stem distribution of the 40 coppice plots measured in the field (see Section 2.1), two virtual forests were generated and placed on the model slope for each forest measured: one with the clumped stem distribution that is characteristic for coppice stands and another one with a random stem distribution.

First, we checked the spatial distribution of stems and stools in the field data using the pair density function $g(r)$, the second-order neighbor density function $n(r)$, and Ripley's $K$ function $K(r)$ and $L$ function $L(r)$ (all included in $k f u n$ in the ads package of R; Pelissier and Goreaud 2010). This revealed that the stools are randomly distributed, whereas the stems display the expected clumped stem distribution (Fig. 1) which is typical for coppice forests (Rozas et al. 2009). Thus, for the virtual forests, we successively sampled stool coordinates from a uniform random distribution until the stool density measured in the field was obtained. After that, the different clumps (all stems of one stool) measured in the field were randomly placed onto the stool coordinates of the virtual forest. For the second stand (CO), where stem coordinates were measured, the single shoots of the field data stools were plugged onto the virtual forest stools, maintaining the clumped distribution. For the first stand (GA), where stem coordinates were not measured, each stool was regarded as an ellipse, and stem coordinates were randomly generated within the stool circumferences, by sampling stem distance and angle 
Fig. 1 Left Model slope where the forest is placed, with measuring lines and rock departure zone (gray bar at the top). Right example of a $20 \times 20$-m detail of the forest with clumped stem distribution (stool positions sampled from a uniform random distribution and stems placed according to field data); circle size represents tree diameter at breast height

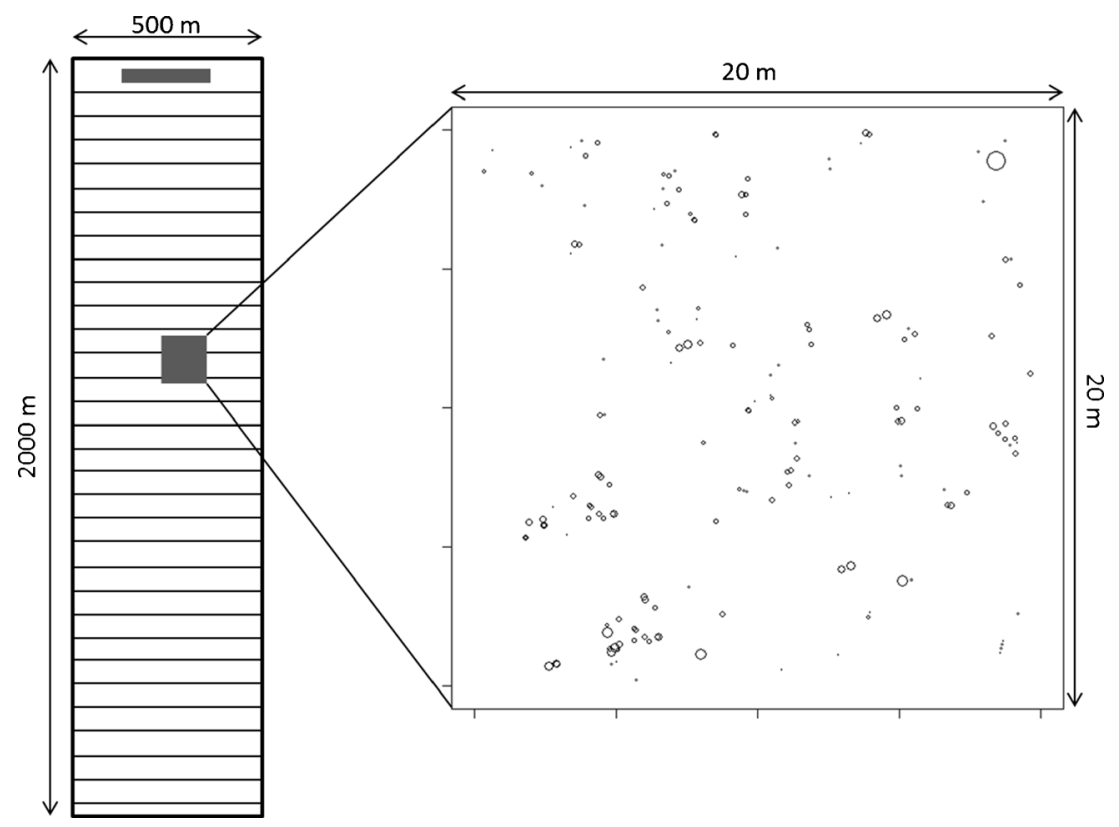

from the stool center from a uniform random distribution. The rest of the proceeding was the same as for stand $\mathrm{CO}$.

For virtual forests with a random stem distribution, stem coordinates were directly generated by sampling from a uniform random distribution based on the field-measured stem density. Diameters were associated with each generated stem by randomly sampling values from the field-measured stem diameters.

\subsection{Data analysis}

The first aim was to represent the multiple readings (for each measuring line) collected for each rockfall protection indicator as a single value for each forest stand. Each of the two serial data indicators, "number of passing rocks" and $E_{95}$, was saved for each measuring line ( $n=200$ for $0.5 \mathrm{~m}^{3}$ rocks, $n=333$ for $0.25 \mathrm{~m}^{3}$ rocks; Table 2 ), resulting in a large amount of data. If a method of representing the significance of this data in a single value for each coppice stand could be identified, the different virtual forests would be compared by using it. For each indicator $I$ defined, the protective effect (PE) of each forest patch $x$ is calculated as follows:

$$
\mathrm{PE}=100-\left(I_{(\text {forest } x)} * 100 / I_{(\text {no forest })}\right)
$$

where $I_{(\text {forest } x)}$ is the value of the indicator for the forest patch $x$, and $I_{\text {(no forest) }}$ is the value of the indicator without forest. PE without forest is $0 \%$, i.e., the forest patch provides no rockfall protection, and $\mathrm{PE}$ is positive if the forest has a beneficial effect and negative, otherwise.

Next, we compared the protection indicated by our processbased model with the classical protection indicator mean tree free distance (MTFD) (Gsteiger 1993) that is calculated as follows:

$$
\text { MTFD }=\frac{10,000}{N^{*}\left(0.9 * \phi_{\text {rock }}\right)+\sqrt{\frac{4 * G}{\pi^{*} N}}}
$$

where $N$ is the stem density per hectare, $G$ is the basal area in square meter per hectare, and $\phi_{\text {rock }}$ is the equivalent diameter

\begin{tabular}{|c|c|c|c|c|}
\hline \multicolumn{5}{|c|}{ Indicators derived from Rockyfor3D simulations } \\
\hline \multicolumn{2}{|c|}{ Indicators for run-out distance } & \multicolumn{2}{|c|}{ Indicators for rock energy } & Resolution \\
\hline No. & $\begin{array}{l}\text { Number of rocks passing a certain measuring line } \\
\text { (out of } 1 \text { million) }\end{array}$ & $E_{95}(\mathrm{~kJ})$ & $\begin{array}{l}95 \% \text { quantile of the energy of all rocks } \\
\text { passing a certain measure line }\end{array}$ & Measuring line \\
\hline$d_{95}(\mathrm{~m})$ & $\begin{array}{l}\text { Run-out distance at which } 95 \% \text { of the rocks are stopped } \\
\text { and extracted from the number of passing rocks }\end{array}$ & - & - & Forest stand \\
\hline $\mathrm{PE}_{d}(\%)$ & Protective effect of a certain forest in relation to no forest cover & - & - & Forest stand \\
\hline \multicolumn{5}{|c|}{ Indicators calculated from stand parameters } \\
\hline $\operatorname{MTFD}(\mathrm{m})$ & $\begin{array}{l}\text { Mean tree free distance calculated based on basal area and stem } \\
\text { density (see equation in Section 2.4) }\end{array}$ & & & Forest stand \\
\hline
\end{tabular}

Table 2 Indicators used in this study to quantify the protective effect of coppice forests 
of the falling rock. The aim was to see if the complexity embedded into process-based model calculations is necessary and if both indicators rank the protective effect of the different forests in the same order.

To test whether the protective effect differs between forests with random or clumped stem distributions, we calculated a paired Wilcoxon signed rank test with the indicators for the protective effect. For that, we used the 21 plots of the second stand (CO) only, but running the simulations once with small and once with big rocks.

To understand how the protective effect of a coppice forest changes during its aging process, we correlated the indicator of the protective effect, if possible, to the following six stand characteristics: basal area, stem density, stool density, multistem percentage (percentage of stools with more than one stem), mean dbh, and standard deviation of $\mathrm{dbh}$. To display the similarities of the 40 forest patches, we conducted a principal component analysis (PCA) (Leyer and Wesche 2007) based on these six stand characteristics. The indicator of the protective effect for the simulations with small and big stones was fitted afterwards (function envfit in the vegan package within R; Oksanen et al. 2012). Based on the six stand characteristics, the forest patches were grouped into three groups with the $K$-means clustering algorithm of Hartigan and Wong (1979; implemented in $\mathrm{R}$ as $k$-means). All statistical analyses were conducted with $\mathrm{R}$ version 2.15.1 (R Core Team 2012).

\section{Results}

\subsection{Defining protection indicators for coppice forests}

The analysis of the $E_{95}$ of the kinetic energy of the rocks in this study revealed that this variable is unsuitable for quantifying the protective effect of the different forests. On the one hand, the results showed little difference between all forest stands in the first meters of the slope. Thus, it is a poor measure to compare the protective effect of different forests. On the other hand, it became noisy and was, therefore, not relevant as an indicator, as soon as the number of rocks passing through the measure line became too low (see Fig. 2; $0.5 \mathrm{~m}^{3}$, distances greater than $120 \mathrm{~m}$ ). The poor quality of this indicator is illustrated by the following unexpected observation: after large rock propagation distances, the indicator $E_{95}$ was larger in simulations with forest cover than in simulations without forest cover, and for long distances, the distribution of the energy of the passing rocks is measured from relatively few passing rocks. This rock number is smaller with forest cover than without forest cover, because the forest has stopped more rocks before a certain distance. The $95 \%$ quantile of the distribution of the rock energy is thus more influenced by the rocks having large energies, which can lead

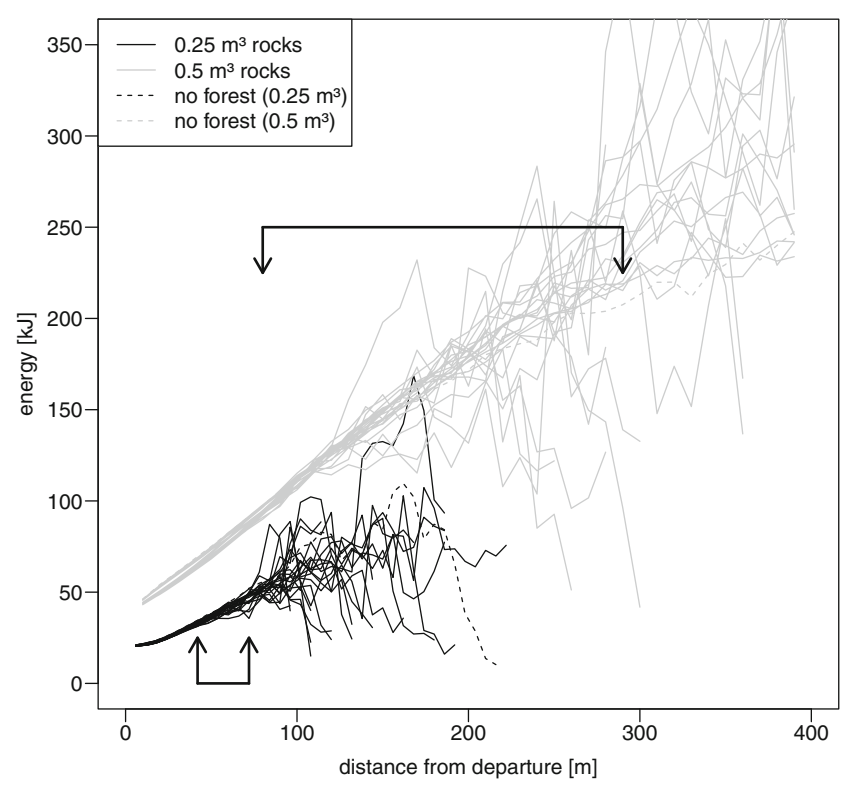

Fig. 2 Development of the $95 \%$ energy quantile $\left(E_{95}\right)$ of the rocks with increasing distance from departure for small and big rocks. Simulations are calculated with the clumped stem distributions of the second stand. One line shows one forest patch, $n=21+$ no forest. Arrows show minimum $d_{99.5}$ and maximum $d_{99.5}$

to unexpectedly large values of $E_{95}$. The higher $E_{95}$ values of forest compared to no forest can also be related with the preferential stopping of low-energy rocks due to impacts against trees. Thus, rocks with low energy levels are more likely to be stopped in the intervening distance between measuring lines in forested simulations, favoring the measurement of rocks retaining high energy levels and therefore increasing the $95 \%$ quantile values from forested simulations relative to no forest.

The analysis of the number of passing rocks showed, as for the $E_{95}$ energy quantile, small differences between the different virtual forests for small propagation distances and slightly noisy values for large propagation distances. However, between these two zones, rock-passing frequencies were stable, and the curves did not cross each other (Fig. 3). Thus, any arbitrary percentage of passing rocks can be chosen to derive an indicator for the protective effect. However, we have extracted the "run-out distance" $d_{99.5}$, as distance from departure in $m$ where $99.5 \%$ of all rocks are stopped, because the differences between the curves increased with an increasing proportion of stopped rocks. At the same time, the number of remaining rocks in propagation is large enough, so that the results are not too noisy. In other words, $d_{99.5}$ is not sensitive to the variability of the simulation results due to the stochastic character of the rockfall simulations coming from the sampling of soil properties at each rebound of the rock and from the location of the trees. An indicator of the protection effect, called $\mathrm{PE}_{d}$, is derived from the values of $d_{99.5}$ obtained for each forest patch. 


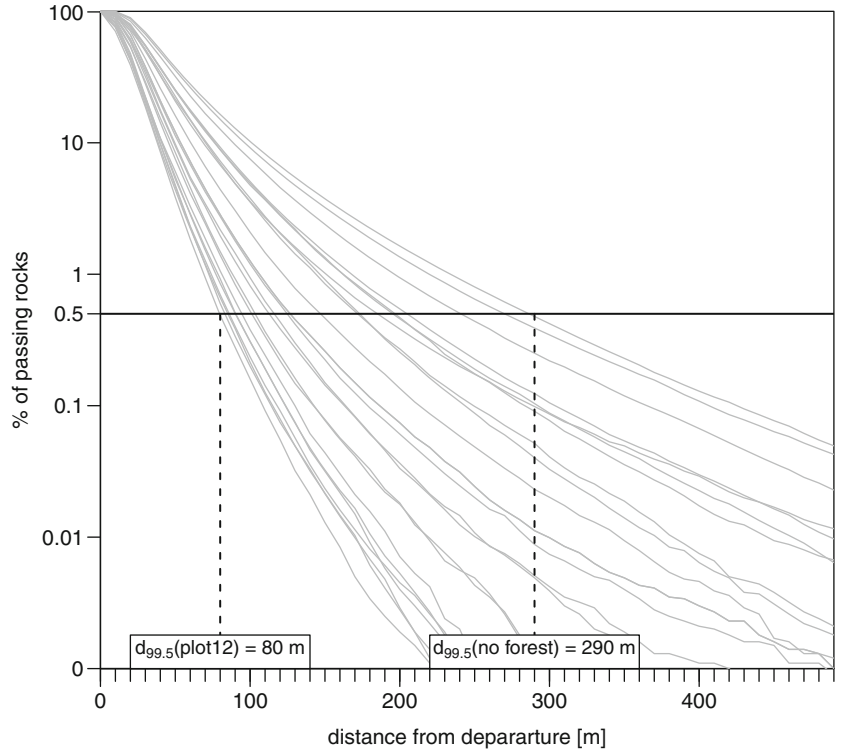

Fig. 3 Extraction of the indicator $d_{99.5}$ from the model results; $d_{99.5}$ is the distance from departure (meters) where more than $99.5 \%$ of the rocks where stopped. Due to the measuring lines, this is in discrete 10-m steps. The gray curves are based on the same simulations as the curves in Fig. 2, but only the results for the big rocks are shown here. The upper line is without forest. Dashed lines are examples for $d_{99.5}$. Note that the $y$-axis is drawn using a logarithmic scale

According to the $\mathrm{PE}_{d}$ indicator, the protective effect of forests is greater when the forest age increases, whereas according to the MTFD indicator, medium-aged forests have a greater protective effect than old-aged ones, and young forest stands have the smallest protective effect (Fig. 4). In other words, the MTFD

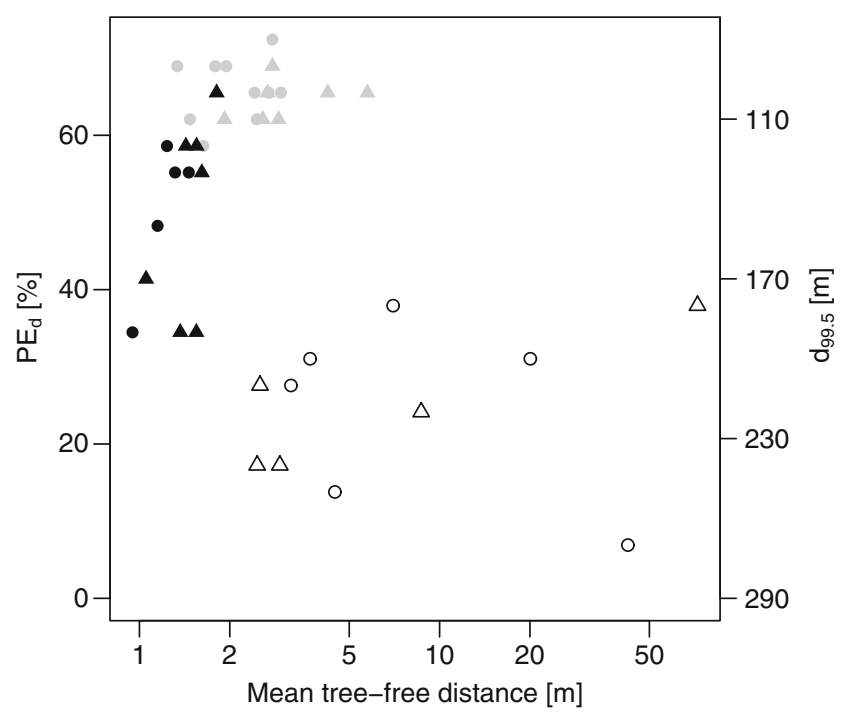

Fig. 4 Comparison of indicators derived from our model simulations (protective effect $\mathrm{PE}_{d}$ and run-out distance $d_{99.5}$ ) with an indicator calculated from stem density and basal area (MTFD) for $0.5 \mathrm{~m}^{3}$ rocks. Age grouping is based on a cluster analysis (see Section 3.3) and the symbols are explained in Fig. 5. Note that the $x$-axis is drawn using a logarithmic scale indicator shows that rocks travel longer without impacting trees in old stands than in medium-aged stands, whereas the $\mathrm{PE}_{d}$ indicator demonstrates that the majority of the rocks are more quickly stopped in older than in medium-aged stands.

\subsection{Difference between random and clumped stem distributions}

The run-out distance $d_{99.5}$ of big rocks $\left(0.5 \mathrm{~m}^{3}\right)$ was lower when stems were randomly distributed $\left(d_{99.5}=132 \pm 72 \mathrm{~m}\right)$ rather than when stems were clumped $\left(d_{99.5}=150 \pm 63 \mathrm{~m}\right.$; paired Wilcoxon test, $V=167.5$, degrees of freedom $(d f)=21, p<0.001)$. This means that the random stem distribution had a higher protective effect compared to the clumped stem distribution. The same was observed for small rocks $\left(0.25 \mathrm{~m}^{3}\right)$; a random stem distribution showed a lower run-out distance $\left(d_{99.5}=47 \pm 11 \mathrm{~m}\right)$ than a clumped stem distribution $\left(d_{99.5}=51 \pm 9 \mathrm{~m}\right.$; paired Wilcoxon test, $V=91$, $d f=21, p<0.001)$. The mean difference in $d_{99.5}$ between random and clumped stem distributions is, however, greater for the big rocks (18 $\mathrm{m}$, which corresponds to $12 \%$ ) than for the small rocks (4 m, which corresponds to $8 \%$ ).

\subsection{Differences between coppice forests of different ages}

The biplot of the PCA displayed the interrelations of the stand characteristics of all 40 forest patches that all belonged to the same cloud without forming distinct groups (Fig. 5).

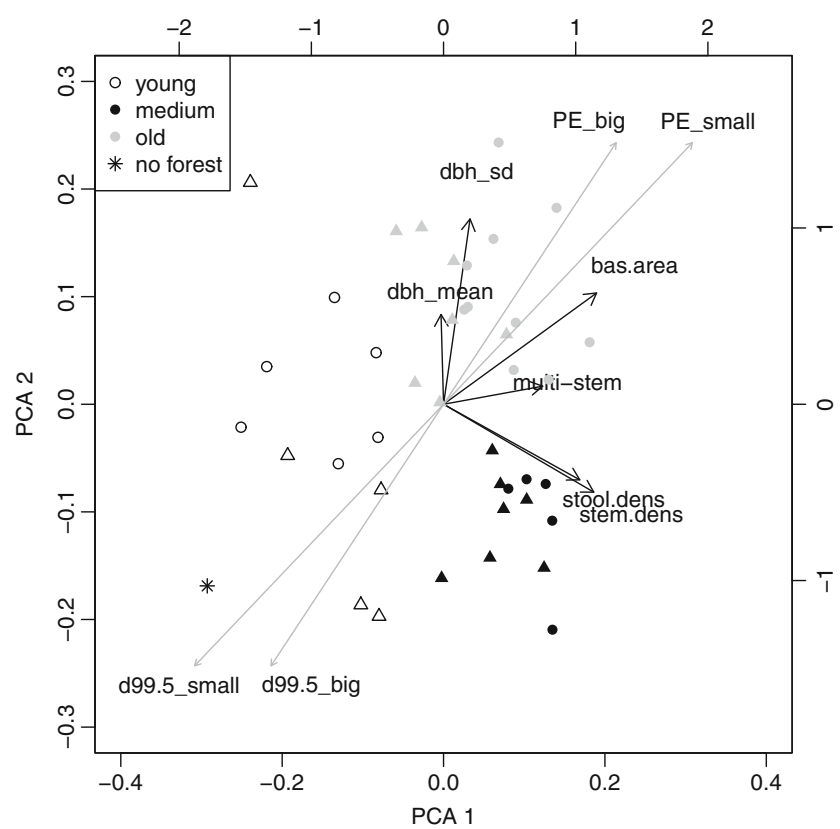

Fig. 5 Biplot of the principal component analysis $(P C A)$ based on six stand characteristics of all 40 forest patches. Protective effect $\mathrm{PE}_{d}$ and run-out distance $d_{99.5}$ for small and big rocks were fitted post hoc. Triangles show the plots in the stand GA, and circles show the plots in $\mathrm{CO}$ 
However, the $K$-means clustering elicited three clear age groups, i.e., without overlap (Fig. 5). The arrow of basal area increased from young and medium patches toward old ones, whereas stem density increased from young and old patches toward medium ones. Stem and stool densities were very much correlated. The arrows of multistem percentage and mean dbh were short, i.e., without describing clear trends between the age groups. The post hoc fit of $d_{99.5}$ for small and big rocks was very good $(p<0.001$ in both cases) and seemed highly correlated with basal area and dbh standard deviation.

The protective effect $\mathrm{PE}_{d}$ against big rocks $\left(0.5 \mathrm{~m}^{3}\right)$ clearly increased with increasing basal area (Fig. 6a). The percentage of multistemmed trees ranged between 0 and $70 \%$ and had no clear influence on the protective effect (Fig. 6b). The relationship between the stem density and the protective effect was not so clear. However, all old forests had a good protective effect (60-70\%), even though they covered a wide range of stem densities, including those with stem densities below 4,000 stems/ha, whereas the $\mathrm{PE}_{d}$ of some of the young forests with similar stem densities was only half as good (Fig. 6c). Stool density and $\mathrm{PE}_{d}$ were not correlated at all (Fig. 6d). The relationship of $\mathrm{PE}_{d}$ to $\mathrm{dbh}$ mean was similar to that of $\mathrm{PE}_{d}$ to basal area, but less linear, and reaches a more sigmoidal plateau. The two outliers were clearings with standards, thus having large mean dbh, but very low stem densities (Fig. 6e). The pattern was similar for the dbh standard deviation, except for the fact that the young forest patches were more dispersed, exhibiting relatively high standard deviations, caused by the standards. Looking only at the young forest patches indicates a positive trend of the protective effect with increasing dbh standard deviation, which suggests that each single tree with a larger diameter increases the
Fig. 6 a-f Protective effect $\mathrm{PE}_{d}$ and run-out distance $d_{99.5}$ in relation to different stand characteristics. The age grouping is based on $K$-means clustering. Triangles show plots in GA, and circles show plots in $\mathrm{CO}$
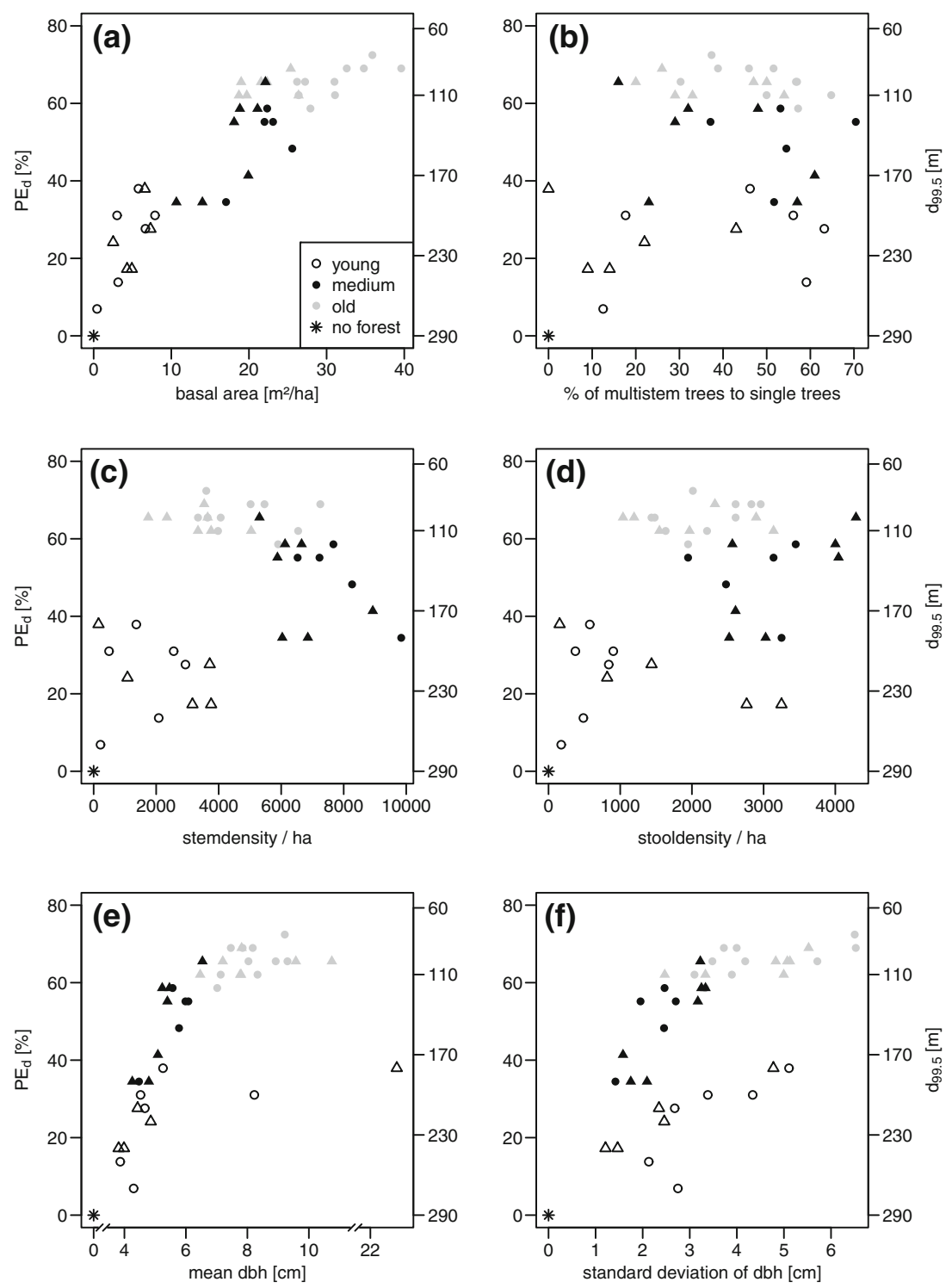
protective effect considerably (Fig. 6f). In conclusion, the protective effect reaches a maximum of about $70 \%$ compared to no forest at a basal area around $20 \mathrm{~m}^{2} / \mathrm{ha}$ and a mean $\mathrm{dbh}$ around $7 \mathrm{~cm}$, corresponding to a maximum reduction of the run-out distance $d_{99.5}$ from $290 \mathrm{~m}$ to about $100 \mathrm{~m}$. However, additional calculations are needed, if one wants to know how coppice forests with larger dbh or basal area influence the protective effect. All patterns were similar for the simulation results of small rocks $\left(0.25 \mathrm{~m}^{3}\right)$. Therefore, these results are not shown.

\section{Discussion and practical implications for silvicultural management}

\subsection{Protection indicators for coppice forests}

Most of the indicators for the protective effect of forest extracted from process-based model results incorporate either the energy of the rocks (Volkwein et al. 2011) or the run-out distance of a certain number of rocks, which is similar to the number of rocks that run until a certain distance (Woltjer et al. 2008) or a combination of both. The quantiles of the kinetic energy of a rock when it exits the forest are relevant indicators for engineering protection structures (Lambert et al. 2013). However, as explained in Section 3.1, the $E_{95}$ was highly variable in our study, with variations depending on the number of rocks passing each measuring line. Therefore, it was not a relevant indicator for coppice forests. In contrast, the run-out distance constantly decreased. Thus, it was a good indicator for distinguishing the protection capacity of different forest stands, especially the extracted $d_{99.5}$ which gives one value per stand only.

The difference between $\mathrm{PE}_{d}$ and MTFD is related to the energy dissipated when a rock impacts a tree, which is incorporated into the process-based model and not in the MTFD indicator. In our simulations, old coppice patches were the most effective in rockfall protection, followed by medium-aged ones, whereas MTFD was lowest for the medium-aged patches followed by the old coppice patches (Fig. 4). At the same time, some old and young patches had the same MTFD, but a very different $\mathrm{PE}_{d}$. This suggests that MTFD is a poor indicator of the rockfall protection capacity of coppice forests, overestimating protection, especially in young and medium-aged forests. The amount of energy that is dissipated when impacting a small-diameter tree in young or medium-aged stands is too low to stop the rock. Old forests, in contrast, provide better protection because the energy dissipation when the rock impacts a larger-diameter tree is, on average, greater. Hence, basal area and dbh are more important for the protective effect against rocks than stem density.
4.2 Difference between random and clumped stem distributions

The result that the forests provided better protection when stems where randomly distributed (theoretical distribution) instead of clumped (real distribution in coppice) can be explained by the bigger gaps in the latter, which decrease the probability of tree impacts for travelling rocks and prolong the trajectory between impacts where the rock can accelerate.

In addition, the more pronounced difference in $d_{99.5}$ between random and clumped stem distributions for big rocks ( $12 \%$, relative to $8 \%$ for small rocks) can be related to the different kinetic energy levels for small and big rocks. A small rock gains less energy when on a trajectory without impacting a tree than a big rock, and so, it is easier to stop when it does collide with a tree. Therefore, the energy levels of small rocks are generally low, so that the differences between random and clumped stem distributions in terms of protection are smaller than for big rocks.

\subsection{Practical implications for coppice age and the role} of standards

For the rock sizes used in our simulations $\left(0.25\right.$ and $\left.0.5 \mathrm{~m}^{3}\right)$, the results clearly showed that the basal area and dbh are more important than stem density. Coppice stands older than 20 years offered a better protection against rockfall than younger ones. Foresters have recommended that the coppice forests on steep slopes are cut at least every 25 years to maintain high stem densities for good rockfall protection (Autonome Provinz Bozen-Südtirol 2010; Gerber and Elsener 1998). The simulation results question this recommendation, as we conclude that the coppice overaging, i.e., exceeding the traditional cycle of 25 years, does not have a negative impact on the protection function, at least for the stands studied which were not older than 60 years. For smaller rock sizes $\left(<0.25 \mathrm{~m}^{3}\right)$, the recommendation of maintaining high stem densities for protection purposes might be held, because smaller rocks have lower energies and are easier to stop even by small-diameter trees. Moreover, a young coppice forest with a high number of stems prevents erosion, stabilizes the ground surface, and prevents smaller rocks from rolling off (Gerber and Elsener 1998). In this respect, coppice clumps might act as combs for smaller rocks that get trapped between the different stems emerging from one stool.

Concerning the influence of tree diameter distribution on the protection effect, the dbh standard deviation was among the important factors in the PCA (long arrow and small angle to the arrow of PE, Fig. 5). Looking only at the young forest patches (including clearings), the positive correlation was clearer between dbh standard deviation and $\mathrm{PE}_{d}$ (Fig. 6e) than between mean dbh and $\mathrm{PE}_{d}$ (Fig. 6f). The protective effect of one of the recently cleared patches (with a few standards 
remaining) was still one third compared to no forest cover (outlier with dbh of $>22 \mathrm{~cm}$ in Fig. 6e). This indicates a positive influence of single, large-diameter trees on the protective effect, even though the relative influences of mean $\mathrm{dbh}$ and $\mathrm{dbh}$ standard deviation or heterogeneity are hard to disentangle. A heterogeneous dbh distribution is recommended for high forests with a protection function role, where it can be assured by a broad age structure of the trees (Frehner et al. 2005). In coppice forest, the synergistic effect of small and large diameter trees can be achieved through a sufficient number of standards that are left for more than one rotation period in the coppice forest. Likewise, impacts on large-diameter stems can result in large reductions in the kinetic energy of rocks, so big rocks can be stopped by subsequent impacts on small trees that would otherwise have had a little effect. Therefore, coppice with standards is to be preferred over simple coppice forests when they have protection function.

\subsection{Research perspectives}

The results obtained in this study, despite their clear and meaningful conclusions, have to be considered in view of the artificial regular slope that was used with one fixed angle and the knowledge gaps concerning the modeling of rockfall hazards on sites covered with coppice forest. The modeling of rock-tree interaction in Rockyfor3D is calibrated to physical processes occurring during impacts on single trees. Consequently, Rockyfor3D has probably underestimated the protective effect of the coppice forests since it does not yet fully incorporate the physical processes occurring during multistem impacts. For clumps (stools with more than one stem), some kind of collective effect can be assumed, i.e., the rock can be in contact with two stems at the same time which may increase the energy dissipation of the coppice structure. This type of interaction needs to be quantified and modeled on the basis of the actual measurements of Jancke et al. (2013), Lundstrom et al. (2009), and Bertrand et al. (2013).

Additionally, broadleaf forests and coppice stands, in particular, have been less subject to rockfall experiments than coniferous forests, since coniferous forests cover a larger area of the Alps. Consequently, little quantitative data is available about the rock energy dissipation on broadleaves, especially with small diameters (Jancke 2012) or other species than beech (Fagus sylvatica; Stokes et al. 2005). A rockfall model adapted to coppice would allow a comparison of different tree species in terms of the spatial configuration of stems within clumps, e.g., Robinia stems usually grow in rows parallel to the contour lines of a slope (own observation), whereas Ostrya, Fraxinus ornus, or Tilia make rather ellipsoidal clumps. Improving rockfall models according to these two points (collective effect within clumps and energy dissipation potential of different broadleaf species) would be of great interest to forest management optimization for rockfall protection.

Acknowledgments Special thanks to Theresa Wagner and Joseph Molyneux for their help in the field, to Giustino Tonon and Verena Larcher for their support with the sampling design, and most importantly, to Oliver Jancke for numerous enlightening discussions about rockfall in coppice forests. Thomas Cordonnier gave valuable advice for the spatial analyses of the tree distributions. The study was supported by the forest service of the Autonomous Province of Bolzano. Joseph Bartho corrected the English. We thank Barry Gardiner and one anonymous reviewer for their very valuable comments to improve the manuscript.

Funding The EcoRAlps project was funded by the Stemmler and Immerschitt foundations within the "Stifterverband für die deutsche Wissenschaft" (Association of Foundations for German Science) and the Foundation of the Free University of Bozen-Bolzano.

\section{References}

Autonome Provinz Bozen-Südtirol (2010) Waldtypisierung Südtirol, Band $1 \& 2$. Bozen

Bertrand D, Bourrier F, Olmedo-Manich I, Brun M, Berger F, Limam I (2013) Experimental and numerical dynamic analysis of a live tree stem impacted by a Mouton Charpy's pendulum. Int J Solids Struct 50:1689-1698

Ciabocco G, Boccia L, Ripa MN (2009) Energy dissipation of rockfalls by coppice structures. Nat Hazards Earth Syst Sci 9:993-1001

Dorren LKA (2012) Rockyfor3D (v4.1) revealed - transparent description of the complete $3 \mathrm{D}$ rockfall model. ecorisQ paper

Dorren LKA, Berger F (2005) Stem breakage of trees and energy dissipation during rockfall impacts. Tree Physiol 26:63-71

Dorren LKA, Berger F, Putters US (2006) Real size experiments and 3D simulation of rockfall on forested and non-forested slopes. Nat Hazards Earth Syst Sci 6:145-153

Dorren LKA, Berger F, Jonsson M, Krautblatter M, Mölk M, Stoffel M, Wehrli A (2007) State of the art in rockfall-forest interactions. Schweiz Z Forstwes 158:128-141

Frehner M, Wasser B, Schwitter R (2005) Nachhaltigkeit und Erfolgskontrolle im Schutzwald. Wegleitung für Pflegemassnahmen in Wäldern mit Schutzfunktion

Gerber C, Elsener O (1998) Niederwaldbetrieb im Steinschlaggebiet. Wald Holz 14:8-11

Gsteiger P (1993) Steinschlag Schutzwald. Ein Beitrag zur Abgrenzung, Beurteilung und Bewirtschaftung. Schweiz Z Forstwes 144:115-132

Hartigan JA, Wong MA (1979) A K-means clustering algorithm. Appl Stat 28:100-108

Jancke O (2012) Quantifying the mechanical resistance of coppice trees against rockfall. University of Hamburg, Germany, Dissertation

Jancke O, Dorren LKA, Berger F, Fuhr M, Köhl M (2009) Implications of coppice stand characteristics on the rockfall protection function. For Ecol Manag 259:124-131

Jancke O, Berger F, Dorren LKA (2013) Mechanical resistance of coppice stems derived from full-scale impact tests. Earth Surf Process Landf 38:994-1003

Jonsson MJO (2007) Energy absorption of trees in a rockfall protection forest. Eidgenössische Technische Hochschule, Switzerland, Dissertation

Lambert S, Bourrier F, Toe D (2013) Improving three-dimensional rockfall trajectory simulation codes for assessing the efficiency of protective embankments. Int J Rock Mech Min Sci 60:26-36

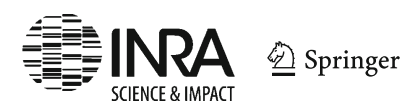


Leyer I, Wesche K (2007) Multivariate Statistik in der Ökologie: Eine Einführung. Springer, Berlin

Lundstrom T, Jonsson MJ, Volkwein A, Stoffel M (2009) Reactions and energy absorption of trees subject to rockfall: a detailed assessment using a new experimental method. Tree Physiol 29:345-359

Matula R, Svatek M, Kurova J, Uradnicek L, Kadavy J, Kneifl M (2012) The sprouting ability of the main tree species in Central European coppices: implications for coppice restoration. Eur J For Res 131: $1501-1511$

Notaro S, Paletto A (2012) The economic valuation of natural hazards in mountain forests: an approach based on the replacement cost method. J For Econ 18:318-328

Oksanen J, Blanchet FG, Kindt R, Legendre P, Minchin PR, O'Hara RB, Simpson GL, Solymos P, Stevens MHH, Wagner H (2012) vegan: community ecology package. $\mathrm{R}$ package version $2.0-3$

Pelissier R, Goreaud F (2010) ads: spatial point patterns analysis. R package version 1.2-10

Piussi P (2006) Close to nature forestry criteria and coppice management. In: Diaci J (ed) Nature-based forestry in Central Europe: alternatives to industrial forestry and strict preservation, vol 126. Studia Forestalia Slovenia, Slovenia, pp 27-37

Piussi P, Farrell EP (2000) Interactions between society and forest ecosystems: challenges for the near future. For Ecol Manag 132: 21-28

Puumalainen J (2001) Structural, compositional and functional aspects of forest biodiversity in Europe (no. ECE/TIM/DP/22). United Nations, Geneva
R Core Team (2012) R: a language and environment for statistical computing. R Foundation for Statistical Computing, Vienna. http://www.R-project.org/. Accessed 22 June 2012

Radtke A, Ambraß S, Zerbe S, Tonon G, Fontana V, Ammer C (2013) Traditional coppice forest management drives the invasion of Ailanthus altissima and Robinia pseudoacacia into deciduous forests. For Ecol Manag 291:308-317

Rozas V, Zas R, Solla A (2009) Spatial structure of deciduous forest stands with contrasting human influence in northwest Spain. Eur J Forest Res 128:273-285

Stokes A, Salin F, Kokutse AD, Berthier S, Jeannin H, Mochan S, Dorren L, Kokutse N, Abd. Ghani M, Fourcaud T (2005) Mechanical resistance of different tree species to rockfall in the French Alps. Plant Soil 278:107-117

Volkwein A, Schellenberg K, Labiouse V, Agliardi F, Berger F, Bourrier F, Dorren LKA, Gerber W, Jaboyedoff M (2011) Rockfall characterisation and structural protection-a review. Nat Hazards Earth Syst Sci 11:2617-2651

Wehrli A, Zingg A, Bugmann H, Huth A (2005) Using a forest patch model to predict the dynamics of stand structure in Swiss mountain forests. For Ecol Manag 205:149-167

Wehrli A, Dorren LKA, Berger F, Zingg A, Schönenberger W, Brang P (2006) Modelling long-term effects of forest dynamics on the protective effect against rockfall. For Snow Landsc Res 80:57-76

Woltjer M, Rammer W, Brauner M, Seidl R, Mohren GMJ, Lexer MJ (2008) Coupling a 3D patch model and a rockfall module to assess rockfall protection in mountain forests. J Environ Manag 87:373-388 